\title{
Penyuluhan Pendidikan Seks dan Mengenal Masa Golden Age pada Anak Usia Dini di TKIT Al-Faqih
}

\author{
Ani Interdiana Candra Sari", Elin Karlina, Fadli Rasam \\ Universitas Indraprasta PGRI \\ *incasani26@gmail.com
}

\begin{abstract}
Abstrak
Maksud diadakan abdimas kegiatan penyuluhan mengenai pendidikan seks pada anak usia dini diharapkan mampu memberikan pengetahuan serta pemahaman kepada wali murid dan guru, sehingga mereka bisa menerapkan kepada peserta didik. Metode yang digunakan adalah observasi, wawancara, dan pelatihan. Berdasarkan penyuluhan yang diadakan diperoleh hasil sebagai berikut: Peserta mampu memahami materi yang diberikan. (2) Peserta mampu menganalisis perkembangan anak berdasarkan karakter. (3) Peserta mampu memotivasi diri supaya bisa menjadi orang tua yang lebih baik lagi. (4) Peserta dapat melakukan analisis mengenai apa yang harus dilakukan pada saat masa golden age. (5) Dapat memperagakan atau memperkenalkan kepada anaknya mengenai pendidikan seks tentang sentuhan yang boleh dan yang tidak boleh.
\end{abstract}

Kata Kunci: pendidikan seks, golden age, pendidik

\section{Sex Education and Knowing the Golden Age Phase in Early Children at TKIT Al-Faqih}

\begin{abstract}
The purpose of holding an outreach activity regarding sex education in early childhood is expected to be able to provide knowledge and understanding to the guardians of students and teachers, so that they can apply it to students. The methods used are observation, interviews, and training. Based on the counseling that was held, the following results were obtained: Participants were able to understand the material given. (2) Participants are able to analyze children's development based on character. (3) Participants are able to motivate themselves so that they can become better parents. (4) Participants can analyze what to do during the golden age. (5) Can demonstrate or introduce to children about sex education about touch which is permissible and not.
\end{abstract}

Keywords: sex education, golden age, educators

\section{PENDAHULUAN}

Pelaksanaan Kegiatan Pengabdian masyarakat ini dilaksanakan di TKIT Al-Faih yang berlokasi di perumahan wahana pondok gede Blok P2 No 22, Kel. Jatisari, Kec. Jatiasih, Kota Bekasi, Jawa Barat. TKIT Al-Faqih merupakan sekolah Islam yang diperuntukkan bagi kalangan menengah ke bawah. TK ini berada dalam lingkungan Perumahan Wahana Pondok Gede. TK ini hanya memiliki tiga guru, dengan jumlah murid 32, yang terdiri dari Play Group, TK A, dan TK B. Wali murid memiliki profesi dan tingkat ekonomi yang beragam. Target peserta kegiatan penyuluhan ini adalah wali murid dan guru TKIT Al-Faqih.

Tingginya angka kekerasan seksual anak merupakan hal yang sangat memprihatinkan, pelaku kekerasan sering dilakukan oleh orang-orang terdekat atau bahkan dilakukan oleh keluarga korban sendiri. Asisten Deputi Bidang Perlindungan Anak dari Kekerasan dan Eksploitasi, Valentina Gintings menyoroti maraknya kasus kekerasan terhadap anak yang terjadi selama pandemi. "Berdasarkan data SIMFONI PPA, pada 1 Januari-19 Juni 2020 telah terjadi 3.087 kasus kekerasan terhadap anak, di antaranya 852 kekerasan fisik, 768 psikis, dan 1.848 kasus kekerasan seksual, angka ini tergolong tinggi (Kemen PPPA, 2020). 
Vol. 2, No. 1, March, 2021, pp. 1-8

e-ISSN: 2722-2004

Sex Education and Knowing

the Golden

Age Phase in Early Children

at TKIT Al-

Faqih

A. I. C. Sari,

E. Karlina,

F. Rasam.

Sepanjang 2019, Komisi Perlindungan Anak Indonesia (KPAI) mencatat, beberapa kasus anak korban pencabulan dan pelecehan seksual di sekolah (Liputan6.com, 2019). Kasus tersebut dilakukan guru dan kepala sekolah, yang terjadi di lingkungan sekolah. Komisioner KPAI Bidang Pendidikan Retno Listyarti menyebut, 20 siswi dari sebuah SD negeri di Malang menjadi korban pelecehan seksual oknum guru honorer.

Meningkatnya kasus kekerasan seksual pada anak merupakan bukti kurangnya pengetahuan anak mengenai pendidikan seks yang seharusnya sudah mereka peroleh dari tahun pertama oleh orang tuanya (Wijhati \& Suharni, 2018). Pandangan masyarakat mengenai pendidikan seks yang masih menganggap tabu menjadi salah satu penyebab anak tidak mendapatkan pendidikan seksual yang benar.

Pendidikan seks semestinya bukan lagi menjadi hal yang tabu bagi masyarakat, bahkan untuk anak-anak (Novita, 2007). Karena hal ini menjadi salah satu modal penting dalam memantapkan seseorang untuk dapat hidup berdampingan dengan lawan jenis tanpa adanya ancaman atau kekhawatiran akan terjadinya tindak kejahatan seksual sebagaimana akhir-akhir ini merebak di masyarakat Indonesia khususnya. Selain itu, pendidikan seks juga berguna untuk membekali individu maupun sosial dalam memperbaiki dan meningkatkan kesehatan reproduksi mereka, mencegah terjadinya penyimpangan seksual, dan sebagainya (Madani, 2003).

Usia dini merupakan masa emas (the golden age) dalam proses tumbuh kembang seorang anak (Zubaedah, 2016). Pada masa ini, anak memiliki kemampuan penyerapan informasi yang pesat, dibandingkan tahap usia selanjutnya. Kepesatan kemampuan otak dalam menyerap berbagai informasi di sekitarnya juga diiringi dengan rasa ingin tahu yang sangat tinggi (Musfiroh, 2009). Maka pada masa ini para orang tua atau pendidik harus memberikan perhatian mereka secara khusus dalam memantau tumbuh kembang si anak. Termasuk yang terpenting di dalamnya adalah terkait dengan pertumbuhan biologisnya, di mana perkembangan seksual anak, terutama pada usia dini mereka, tidak berjalan — atau jangan dibiarkan untuk berjalan — dengan sendirinya. Sebab mereka membutuhkan bantuan, arahan dan segala perhatian khusus yang harapannya perkembangan seksual anak tidak salah arah dan berkembang secara normal sesuai dengan anak pada umumnya (Ronosulistyo, Hanny, M, Seto, 2008).

Clara Kriswanto, psikolog Jagadnita Consulting, dalam bukunya Seks, Es Krim dan Kopi Susu, mengingatkan bahwa pendidikan seks untuk anak harus dimulai sejak dini, bahkan sejak usia 0-5 tahun (masa balita). Proses ini akan berlangsung hingga anak mencapai tahap remaja akhir.

Pendidikan seks yang ditanamkan sejak dini akan mempermudah anak dalam mengembangkan harga diri, kepercayaan diri, kepribadian yang sehat, dan penerimaan diri yang positif. Di sini peran orang tua benar-benar penting. Merekalah yang paling mengenal kebutuhan anak, paling tahu perubahan dan perkembangan diri anak, serta bisa memberi pendidikan seks secara alamiah sesuai tahap-tahap perkembangan yang terjadi. Salah satu cara mengenalkan seks pada anak usia dini adalah dengan cara:

1. Mengenalkan anak anatomi bagian tubuhnya, serta menjelaskan fungsi setiap bagian dengan bahasa sederhana. Misalnya dengan mengatakan bahwa tubuhnya adalah karunia yang sangat berharga dan harus dijaga dengan baik. 
2. Membangun kebiasaan positif. Misalnya, tidak berganti baju di tempat terbuka, tidak pipis di sembarang tempat, serta menutup aurat atau bagianbagian yang tidak pantas dilihat orang lain.

3. Menanamkan pentingnya menjaga organ tubuh tertentu, seperti alat vital, dari sentuhan orang lain. Tentu saja, disertai penjelasan sederhana yang bisa ia terima dan mengerti dengan baik.

4. Membiasakan anak berpakaian sesuai identitas kelaminnya sejak dini. Banyak kelalaian orang tua untuk hal ini. Mereka membuat anak perempuan menjadi tomboy dan anak laki-laki menjadi feminin. Dalam kondisi ekstrem, anak bahkan bisa mengalami kebingungan identitas seksual (Kriswanto, 2005).

Weerakon (dalam Sukarmasi, 2014), juga menekankan pentingnya pendidikan seks sejak usia dini. Tidak berbicara pada anak tentang seks demi pembelajarannya, berarti kita memberikan kesempatan pada mereka saat remaja nanti beralih ke internet untuk mendapatkan pendidikan seks. Menurutnya pendidikan seks pada anak bisa dilakukan dengan tahapan-tahapan berikut:

\section{Usia 0-3 tahun}

Di usia ini, orang tua atau pengajar di kelompok bermain sudah bias mengenalkan nama-nama tubuh yang sebenarnya seperti vagina, penis, atau vulva. Selain itu, anak juga diajari perilaku yang boleh di rumah dan di tempat umum. Misalnya dengan mengajari memakai handuk setiap keluar mandi; membiasakan anak menutup bagian-bagian tubuh tertentu dan melindunginya dari pandangan orang lain, contoh ketika anak membuka bagian tubuh tertentu, maka kita akan mengatakan, "Ih, malu, Nak. Ditutup ya!"

\section{Usia 4-5 tahun}

Ketika usia ini, anak-anak sudah bias diajari tentang nama-nama dari bagian tubuh internal dan eksternal utama. Khususnya bagian reproduksi. Orang tua sudah mulai bisa menjelaskan bagaimana seorang bayi bisa berada di rahim sang ibu tentunya dengan bahasa yang disesuaikan dengan usia anak dan tidak terlalu vulgar.

\section{Usia 6-8 tahun}

Di usia ini, orang tua sudah mulai menjelaskan kepada anak-anak tentang apa yang akan terjadi ketika mereka mulai pubertas sebagai bentuk persiapan anak ketika mengalami masa pubertas nanti.

\section{Usia 9-12 tahun}

Di usia ini, orang tua atau pendidik sudah bias mengajarkan bahwa perubahan yang mereka lalui seperti menstruasi, ereksi, dan ejakulasi adalah hal yang normal. Orang tua bisa memulai membahas penting dan berharganya diri serta tubuh mereka. Untuk mengantisipasi pengaruh media dan internet, batasi apa yang sebaiknya mereka bisa akses dan yang tidak dengan mengontrol anak sebaik mungkin.

\section{Usia 13-18 tahun}

Remaja di usia ini sudah mulai tertarik terhadap lawan jenis. Oleh karenanya, sah-sah saja ketika orang tua membahas tentang cinta, keintiman, dan cara 
Vol. 2, No. 1, March, 2021, pp. 1-8

e-ISSN: 2722-2004

Sex Education and Knowing

the Golden

Age Phase in Early Children

at TKIT Al-

Faqih

A. I. C. Sari,

E. Karlina,

F. Rasam.

mengatur batas dalam hubungan mereka dengan lawan jenis. Orang tua bias mengaji anak tentang hubungan dengan teman sebaya, konflik yang mungkin dialami dan kemungkinan-kemungkinan yang akan terjadi guna membantu anak agar terhindar dari situasi yang tidak mengenakkan mereka (Sukarmasi, 2014).

Dari beberapa penjelasan di atas, bisa ditarik kesimpulan bahwa pendidikan tentang seks memang sangat penting bagi pembekalan bagi anak di usia-usia berikutnya. Selain itu, setiap masa dan umur anak usia dini memiliki kesiapan mental yang berbeda-beda sehingga materi yang disampaikan pun berbeda-beda disesuaikan dengan kemampuan dan tingkat pemahaman mereka tentang pendidikan seks.

Pengabdian masyarakat ini akan mengajak orang tua wali murid dan ibu guru untuk menanamkan pendidikan seks pada anak usia dini dan selalu mendampingi mereka agar tercipta generasi Indonesia yang sehat, cerdas, dan saleh atau saleha. Dengan adanya pendidikan seks ini, diharapkan anak-anak mengerti setiap bagian tubuh dan fungsinya, jadi mereka akan menjadi lebih paham bagian tubuh yang boleh disentuh dan bagian tubuh yang tidak boleh disentuh oleh orang asing, sehingga anak-anak akan lebih menjaga dan menghargai tubuhnya.

Hasil dari pengabdian masyarakat ini akan dipublikasikan dalam bentuk jurnal yang diharapkan dapat memberi kontribusi dalam pendidikan, khususnya pendidikan seks pada anak usia dini.

\section{METODE PELAKSANAAN}

Kegiatan ini dilaksanakan pada Jumat, 19 Juni 2020 pukul 08.00-14.00 WIB di Perumahan Wahana Pondok Gede. Kegiatan ini merupakan penyuluhan mengenai pendidikan seks pada anak usia dini dan masa golden age anak. Dalam penyuluhan ini diberikan beberapa kegiatan yang meliputi penyajian materi untuk orang tua murid dan guru oleh instruktur yang berpengalaman dalam bidangnya.

Metode kegiatan ini dilaksanakan melalui beberapa tahap, yaitu:

1. Observasi langsung. Tim pengabdian masyarakat langsung datang ke lokasi pengabdian untuk memperolah data. Hal ini dilakukan pada saat menjelang kegiatan maupun saat kegiatan berlangsung. Pada saat menjelang kegiatan hal yang pertama kali kami lakukan adalah meminta ijin secara informal dengan Ketua Yayasan TKIT Al-Faqih dengan Umi menentukan peserta yang akan diberikan penyuluhan. Observasi ini berguna untuk mengetahui kondisi peserta dan lokasi serta untuk mewujudkan kesuksesan kegiatan pengabdian masyarakat itu sendiri.

2. Wawancara. Wawancara kami lakukan dengan Ketua Yayasan, Guru, dan wali murid TKIT Al-Faqih.

3. Penyuluhan, yaitu: tim memberikan penyuluhan secara langsung kepada orang tua murid dan guru di TKIT Al-Faqih. Penyuluhan dilakukan 1 kali tatap muka. Adapun tahapan pelaksanaan program yaitu sebagai berikut:

1. Persiapan

Sebelum pelaksanaan penyuluhan tentunya dilakukan persiapan guna kelancaran pelatihan. Persiapan yang kami lakukan antara lain:

a. Survei tempat pelaksanaan kegiatan.

b. Merancang program dan metode penyuluhan. 
c. Pembuatan materi penyuluhan.

d. Mengoordinasikan jadwal penyuluhan dengan TKIT Al-Faqih.

e. Koordinasi dalam penyediaan fasilitas penyuluhan seperti laptop, proyektor dan sarana prasarana.

2. Pelaksanaan Penyuluhan

Kegiatan pengabdian akan dilaksanakan setelah semua perizinan dan persiapan baik perlengkapan maupun peralatan sudah siap digunakan

a. Target kuota kegiatan penyuluhan ini adalah 30 orang tua murid dan 5 guru.

b. Penyuluhan akan dilaksanakan sesuai dengan kesepakatan dengan TKIT Al-Faqih.

c. Penyuluhan diselenggarakan dengan pemaparan materi.

\section{HASIL DAN PEMBAHASAN}

Mitra pengabdian masyarakat yang menjadi objek dalam kegiatan penyuluhan pendidikan seks dan mengenal masa golden age pada anak usia dini beranggotakan guru, kepala sekolah, dan wali murid TKIT Al-Faqih Perumahan Wahana Jatiasih Bekasi.

Kondisi pandemik dan tim abdimas harus mematuhi peraturan PSBB yang berlaku, maka jumlah yang mengikuti penyuluhan hanya dibatasi sebanyak 20 yang terdiri dari pada wali murid kelas B sebanyak 15 wali murid, 4 orang guru, dan 1 kepala sekolah. Pelaksanaan abdimas bertepatan dengan acara syukuran perpisahan kelas B.

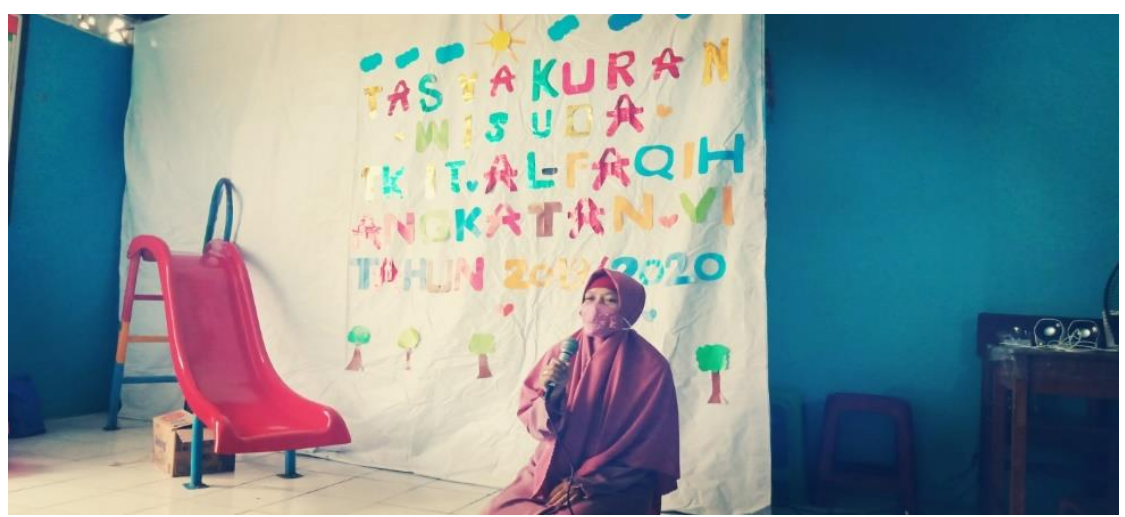

Gambar 1. Sambutan Kepala Sekolah TKIT Al-Faqih oleh Siti Suryani, S.Pd.

Berdasarkan pelaksanaan pengabdian masyarakat yang dilaksanakan dalam masa pandemik ini, pelaksanaan abdimas dilakukan secara tatap muka dengan mematuhi protokol kesehatan (memakai masker, setiap peserta dan tim abdimas harus mencuci tangan terlebih dahulu, dan melakukan jaga jarak). Kendala yang dihadapi adalah waktu penyuluhan terbatas. Adanya keterbatasan dalam fasilitas pendukung untuk melakukan penyuluhan, dikarenakan masa pandemik yang harus membatasi dalam segala hal, sehingga tim abdimas tidak dapat menggunakan game sebagai sarana untuk mempererat hubungan orang tua dengan anak. Saat abdimas bertepatan dengan syukuran perpisahan kelas B, sehingga menjadi tidak fokus. Meskipun memiliki keterbatasan saat penyuluhan, tetapi tidak mengurangi semangat mereka. Peserta memiliki kemauan yang kuat untuk menambah pengetahuan dan pemahaman mengenai bagaimana cara menanamkan pendidikan seks pada anak usia 
Vol. 2, No. 1, March, 2021, pp. 1-8

e-ISSN: 2722-2004

\section{Sex Education and Knowing \\ the Golden \\ Age Phase in Early Children at TKIT Al- Faqih \\ A. I. C. Sari, E. Karlina, F. Rasam.}

dini dan memahami fase golden age anak. Hal ini dapat dilihat dari antusias peserta dalam mengikuti penyuluhan. Peserta memiliki minat dan keinginan untuk mengaplikasikan materi yang telah disampaikan dalam tumbuh kembang anak. Peserta antusias dalam tanya jawab mengenai tumbuh kembang anak. Kegiatan penyuluhan ini disambut baik oleh wali murid, guru, kepala sekolah, ketua yayasan TKIT Al-Faqih Perumahan Wahana Jatiasih Bekasi yang secara langsung ataupun tidak langsung meminta agar bentuk kegiatan seperti ini diadakan berkesinambungan/berkelanjutan sehingga dapat langsung dirasakan manfaatnya bagi wali murid dan guru.

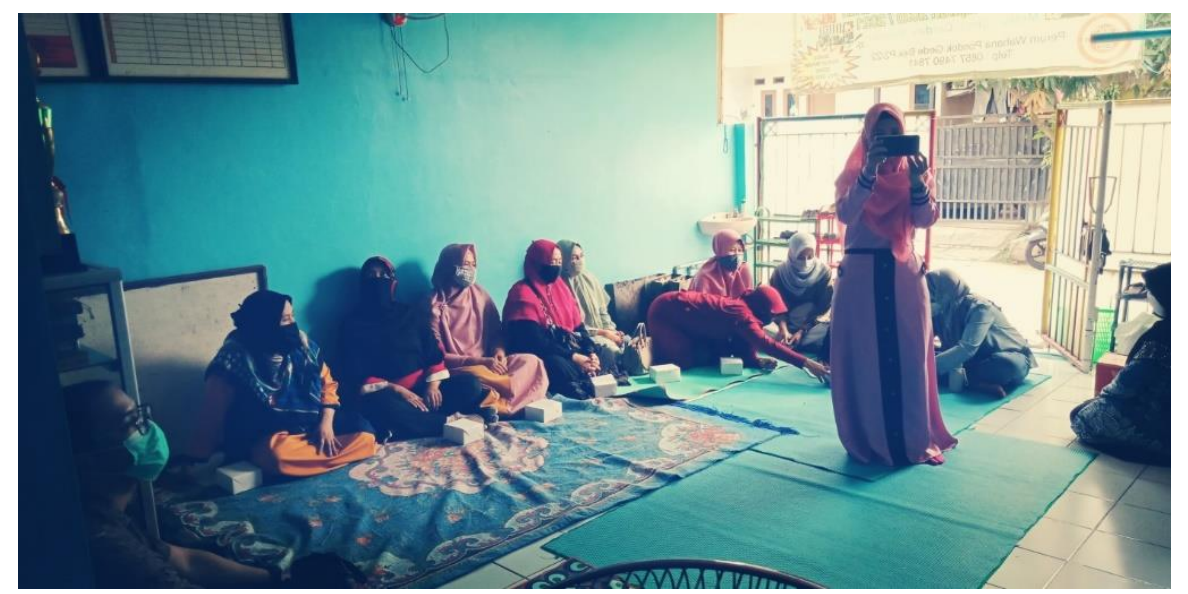

Gambar 2. Kegiatan abdimas menanamkan pendidikan seks dan mengenal masa golden age pada anak usia dini

\section{Pemberian Materi Menanamkan Pendidikan Seks Pada Anak Usia Dini}

Materi yang kami berikan adalah materi tentang menanamkan pendidikan seks pada anak usia dini yang terdiri dari:

a. Hal-hal yang diajarkan ke anak mengenai pendidikan seks

b. Tahapan perkembangan seksual

c. Video

Pemberian materi mengenai Masa Golden Age

Materi yang kami berikan, yaitu materi tentang teori mengenai:

a. Fase Emas Anak

b. Hal yang dilakukan saat masa emas anak

c. Menanamkan masa emas anak menurut Dorothy Law Nolte

Pelaksanaan pengabdian masyarakat mengenai penyuluhan pendidikan seks dan mengenal masa golden age pada anak usia dini di TKIT Al-Faqih Perumahan Wahana Jatiasih Bekasi, dilakukan oleh tim yang berjumlah 3 orang dosen dari universitas Indraprasta PGRI. Tempat pelatihan dilaksanakan di TKIT Al-Faqih Perumahan Wahana Jatiasih Bekasi.

Berdasarkan penyuluhan yang telah dilaksanakan diperoleh hasil sebagai berikut:

1. Peserta mampu memahami materi yang diberikan

2. Peserta mampu menganalisis perkembangan anak berdasarkan karakter

3. Peserta mampu memotivasi diri supaya bisa menjadi orang tua yang lebih baik lagi. 
4. Peserta dapat melakukan analisis mengenai apa yang harus di lakukan pada saat masa golden age.

5. Dapat memperagakan atau memperkenalkan kepada anaknya mengenai pendidikan seks tentang sentuhan yang boleh dan yang tidak boleh.

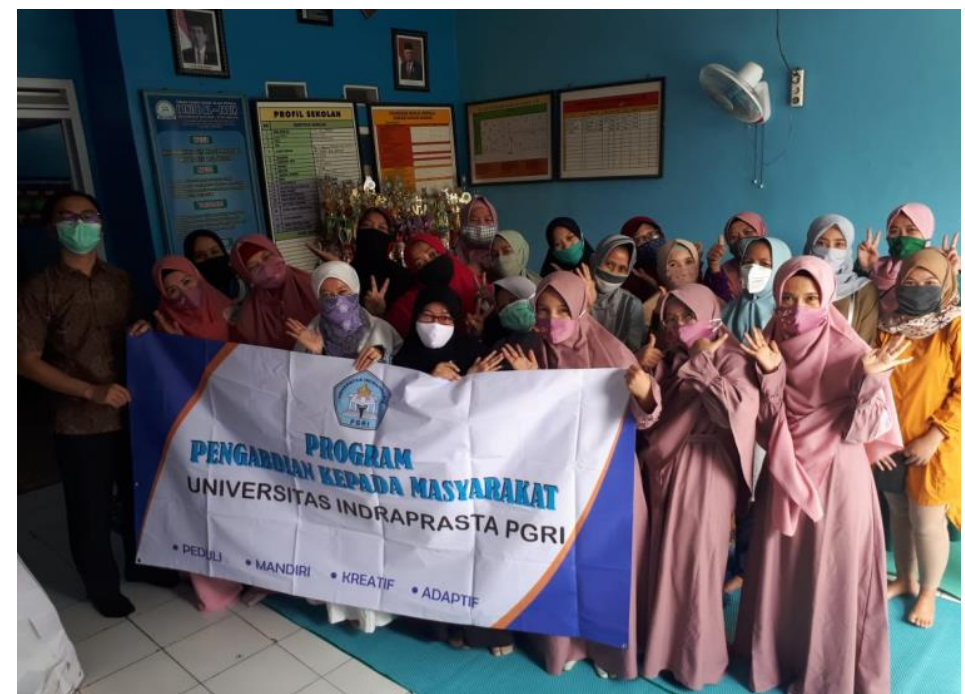
journal published by Neolectura, issued three times in one year. KANGMAS is a scientific publication media in the form of conceptual paper and field research related to social service work.

It is hoped that KANGMAS can become a media for academics and researchers to publish their social service work and become a reference source for the development of social and humanity.

Gambar 3. Foto Bersama Tim Abdimas dan Peserta Abdimas (Guru dan wali murid TKIT Al-

$$
\text { Faqih) }
$$

Sesuai dengan pendapat Chomaria (2011) yang menyatakan bahwa anggapan yang tidak tepat tentang pendidikan seks menyebabkan orang tua enggan memberikan pendidikan seksual pada anak (Wijhati \& Suharni, 2018).

Menurut Adi (2005) pendidikan seks adalah usaha pemberian informasi kepada anak tentang kondisi fisik sebagai perempuan dan laki- laki dan konsekuensi psikologis yang berkaitan dengan kondisi tersebut. Pendidikan seks terdiri dari organ reproduksi, kehamilan, tingkah laku seksual, alat kontrasepsi, kesuburan, menopause serta penyakit kelamin. Dengan memberikan pendidikan seks sedini mungkin pada anak, makan orang tua dapat mencegah pergaulan bebas dan dapat mencegah anak menjadi korban pelecehan seksual (Priyatna dalam Wijhati \& Suharni, 2018).

\section{SIMPULAN}

Dari kegiatan Program Pengabdian Masyarakat yang telah kami laksanakan di TKIT Al-Faqih Perumahan Wahana Jatiasih Bekasi, maka ada beberapa hal yang kami simpulkan yaitu:

1. Orang tua murid, guru, dan kepala sekolah TKIT Al-Faqih Perumahan Wahana Jatiasih Bekasi (penyuluhan mengenai pendidikan seks dan mengenal masa golden age pada anak usia dini) berdasarkan hasil umpan balik didapatkan informasi bahwa kegiatan ini sangat relevan dengan kebutuhan para peserta untuk menambah wawasan dalam tumbuh kembang anak, selain itu peserta bisa memanfaatkan waktu luang untuk belajar menjadi pendidik yang bisa menjadi panutan dan suri teladan yang baik bagi anak-anak.

2. Besarnya minat peserta untuk mengikuti penyuluhan, namun tidak diimbangi dengan daya dukung dan ketersediaan waktu yang cukup singkat. 
Vol. 2, No. 1, March, 2021, pp. 1-8

e-ISSN: 2722-2004

Sex Education and Knowing

the Golden

Age Phase in Early Children

at TKIT AlFaqih

A. I. C. Sari,

E. Karlina,

F. Rasam.

\section{DAFTAR PUSTAKA}

Kemen PPPA. (2020). Angka kekerasan terhadap anak tinggi di masa pandemi Kemen PPPA sosialisasikan protokol perlindungan anak. https://www.kemenpppa.go.id/index.php/page/read/29/2738/angkakekerasan-terhadap-anak-tinggi-di-masa-pandemi-kemen-pppasosialisasikan-protokol-perlindungan-anak

Kriswanto, K. (n.d.). Seks, Es Krim, dan Kopi Susu. Jakarta: Agro Media Pustaka

Madani, Y. (2003). Pendidikan Seks untuk Anak dalam Islam: Panduan bagi Orang Tua, Guru, Ulama, dan Kalangan Lainnya. Jakarta: Pustaka Zahra.

Musfiroh, T. (2009). Menumbuhkembangkan Baca-Tulis Anak Usia Dini. Jakarta: Grasindo,.

Novita, W. (2007). Serba-Serbi Anak yang Perlu Diketahui Seputar Anak dari Dalam Kandungan hingga Masa Sekolah (Tinjauan Psikologis dan Kedokteran). Jakarta: Elex Media Komputindo.

Ronosulistyo, Hanny, M, S. (n.d.). Ketika Anak Bertanya Seks. Jakarta: Grasindo.

Sukarmasi, R. N. (2014). Cara Praktis Ajarkan Pendidikan Seks Dini Sesuai Tahapan Umur Anak dalam m.detik.com/health/read/2014/ 04/29/15126/2568809/cara-praktis-ajarkan-pendidikan-seks-sejak-dinisesuai-tahapan-anak.

Wijhati, E. R., \& Suharni, S. (2018). Pelatihan pendidikan seks anak usia dini pada Kader 'Aisyiyah Ranting Pandeyan Kecamatan Umbulharjo Kota Yogyakarta. AKSIOLOGIYA: Jurnal Pengabdian Kepada Masyarakat, 2(1), 82. https://doi.org/10.30651/aks.v2i1.1308

Zubaedah, S. (2016). Pendidikan seks pada anak usia dini di Taman Kanak-Kanak (TK) Islam Kota Yogyakarta. Al Athfal: Jurnal Pendidikan Anak, 2(2), $55-68$.

suka.ac.id/tarbiyah/index.php/alathfal/article/view/1267 